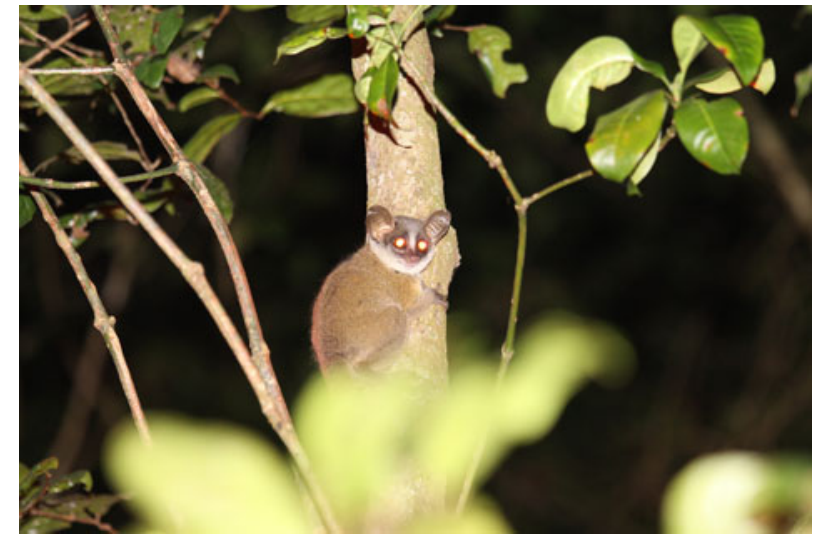

The Taita Mountain dwarf galago Paragalago sp. photographed in Ngangao Forest in 2019. Photo: Hanna Rosti.

of which was successful. We regularly observed dwarf galagos hunting insects on small trees with a trunk diameter of 2-4 cm. We also observed galagos both descending to the ground and ascending to the forest canopy at c. $50 \mathrm{~m}$. In the morning group members made loud incremental calls close to their nest site. The Ngangao group used several tree hollows as daytime sleeping sites, moving every few days. We heard and recorded incremental contact calls irregularly throughout the night. Because of the small size of this population, and predation pressure, its future in Ngangao Forest is bleak. In the larger Mbololo Forest we heard dwarf galagos throughout the fragment, although they were shy and our visual observations were few and brief. Recordings of calls were inconclusive as a diagnostic taxonomic tool as we did not hear incremental calls (a screech was used as a contact call).

The taxonomy of the Taita Mountain dwarf galago remains unclear. Dwarf galagos are cryptic, nocturnal species that are most easily recognized from their vocalizations. Our photographs and recordings of vocalizations suggest that the galago of the Taita Hills is related to the Kenya coast dwarf galago Paragalago cocos (Simon Bearder, Thomas Butynski, Yvonne de Yong, Andrew Perkin and Magdalena Svensson, pers. comms). The Kenya coast dwarf galago Paragalago cocos is known only from low elevations $(<250 \mathrm{~m})$, however, and not from montane forests. Our observations suggest the taxon is highly dependent on hollow trees for refuge and as daytime sleeping sites. The remaining forest fragments must be protected to ensure the survival of the Taita Mountain dwarf galago and other endemic animal species. Molecular analysis, ecology and estimates of population size are needed urgently, to facilitate full identification and an assessment of the taxon for the IUCN Red List. This taxon appears to be already on the brink of extinction.

HaNNa Rosti (@ orcid.org/0000-0003-4495-4183), JoUKO RIKKINEN (๑ orcid.org/0000-0002-4615-6639) and Petri PelLIKKA* University of Helsinki, Helsinki, Finland E-mail hanna.z.rosti@helsinki.fi
SIMON BEARDER Nocturnal Primates Research Group, Oxford Brookes University, Oxford, UK

James Mwang'ombe Mwamodenyi Kenya Forest Service, Kenya

${ }^{*}$ Also at: Taita Research Station, Wundanyi, Kenya

\section{Privately funded land purchase programme in Pushpagiri Wildlife Sanctuary, India}

Habitat fragmentation and loss are the most serious threats to biodiversity and ecological integrity. In this context, privately held land enclaves within the biologically rich Western Ghats of India have negative impacts on biodiversity, including within protected areas. These impacts include persecution of wildlife arising from negative human-wildlife interactions, and overgrazing, firewood collection and illegal hunting.

To address this issue, the Wildlife Conservation SocietyIndia is using an innovative habitat consolidation project to facilitate the voluntary relinquishment of such privately owned land to the state government, for the specific purpose of amalgamating such land with adjacent protected areas. The compensation to the land owner is paid directly by Wildlife Conservation Society-India (WCS-India) on mutually agreed terms. This facilitates the consolidation and intactness of critical wildlife habitats while ensuring that people willing to sell (often so that they can avoid conflict with wildlife, or secure improved access to basic amenities, healthcare and markets) are able to get a fair market value for their property.

To increase support for this programme, the State Government of Karnataka has issued a Government Order that allows civil society organizations to raise funds, buy land in important biodiversity areas or critical corridor sites, and transfer the land to the government. Since 2004 (WCS-India) has purchased property from a total of 75 willing families in Nagarahole Tiger Reserve, Brahmagiri Wildlife Sanctuary, Pushpagiri Wildlife Sanctuary, Kudremukh National Park and Kali Tiger Reserve in Karnataka. A total area of 137 acres (c. 55 ha) has been added to these protected areas.

During September 2019 (WCS-India) negotiated with a society that, as a private land owner, held 5.45 acres (c. $2.2 \mathrm{ha}$ ) inside the Pushpagiri Wildlife Sanctuary. On 9 September the society relinquished their rights over this property to the Government of Karnataka. Eventually this land will become part of Pushpagiri Wildlife Sanctuary.

Prakriti Srivastava, P.M. Muthanna and Sahila Kudalkar (D orcid.org/0000-0002-9762-1537) Wildlife Conservation Society-India, Bengaluru, Karnataka, India E-mail psrivastava@wcs.org 